\title{
Air sampling by pumping through a filter: effects of air flow rate, concentration, and decay of airborne substances
}

\author{
Marko Šoštarić, Branko Petrinec, and Dinko Babić \\ Institute for Medical Research and Occupational Health, Zagreb, Croatia
}

[Received in September 2016; CrossChecked in September 2016; Accepted in November 2016]

\begin{abstract}
This paper tackles the issue of interpreting the number of airborne particles adsorbed on a filter through which a certain volume of sampled air has been pumped. This number is equal to the product of the pumped volume and particle concentration in air, but only if the concentration is constant over time and if there is no substance decomposition on the filter during sampling. If this is not the case, one must take into account the inconstancy of the concentration and the decay law for a given substance, which is complicated even further if the flow rate through the filter is not constant. In this paper, we develop a formalism which considers all of these factors, resulting in a single, compact expression of general applicability. The use of this expression is exemplified by addressing a case of sampling airborne radioactive matter, where the decay law is already well known. This law is combined with three experimentally observed time dependences of the flow rate and two models for the time dependence of the particle concentration. We also discuss the implications of these calculations for certain other situations of interest to environmental studies.
\end{abstract}

KEY WORDS: air sampling filters; particle concentration; radioactivity; substance decomposition

Air sampling for the purpose of determining the concentration $(n)$ of an airborne substance is frequently carried out by pumping air through a sampling filter. The filter is subsequently subjected to an appropriate analysis and $n$ should then be calculated from observables such as the volume $(V)$ of the pumped air and the number $\left(N_{\mathrm{F}}\right)$ of the substance atoms or molecules adsorbed on the filter. The formula $n=N_{\mathrm{F}} / V$ is valid only if $n$ is constant during the sampling and the substance remains stable after it has been deposited onto the filter, which is not always the case (e.g., because of a radioactive decay or a spontaneous chemical decomposition). Generally speaking, one often has to develop a specific model for interpreting the relation between $n, N_{\mathrm{F}}$, and $V$ rather than rely on the abovementioned simple ratio. For instance, a common outcome of such modelling is the correction to the calculated $n$ (which is assumed to be constant) of a radioactive substance that has the half-life $T_{1 / 2}$ of the order of the sampling time $T_{S}(1)$. The situation may become even more complicated if the flow rate $\varphi$ through the sampling filter also changes over time $t$, as demonstrated in the case of an exponentially decreasing $\varphi(t)(2)$. Hence, inconstant $n(t)$ and/or $\varphi(t)$, as well as the decay of substances on the filter, cause deviations from $N_{\mathrm{F}}=n V$, which should not be neglected.

In this paper, we develop a formalism that accounts for the interpretation of $N_{\mathrm{F}}\left(T_{S}\right)$, which is $N_{F}$ at the end of a sampling at $t=T_{S}$, in situations when a substance of interest decays over time, while either (or both) $n(t)$ and $\varphi(t)$ may

Correspondence to: Branko Petrinec, $\mathrm{PhD}$, Institute for Medical Research and Occupational Health, Radiation Protection Unit, Ksaverska cesta 2, HR-10001 Zagreb, e-mail: petrinec@imi.hr be inconstant during the sampling. The profile of $\varphi(t)$ is determined by the characteristics of a particular sampling system (e.g., reduction of filter porosity as the adsorption progresses, changes in meteorological conditions or in the functioning of the pumping system, etc.) and should be available experimentally by using appropriate flow-rate meters. The decay law can be inferred by understanding the general properties of a substance of interest. The issue of $n(t)$ is less straightforward and is a subject of appropriate modelling with regard to other relevant information. Bearing the above in mind, we derived a single expression that can be used in every case where the inputs to it $(\varphi(t)$, $n(t)$, and the decay law for a substance) are available from separate considerations.

In order to illustrate the applications of the mentioned expression, we focus on investigations of radioactive matter suspended in air. This is a case where the decay law is well known and $n(t)$ can be modelled to fit with certain realistic situations. Selected forms of $\varphi(t)$ (i.e., constant, exponentially decreasing, and linearly decreasing) - which have all been observed experimentally - are addressed together with certain profiles of $n(t)$. We first turn to constant $n(t)$, which is a good approximation in the routine monitoring of the presence of radionuclides known to maintain a fairly constant concentration over prolonged time periods (e.g., cosmogenic ${ }^{7} \mathrm{Be}$ with $T_{1 / 2}=53.4$ days). Then we consider a sudden increase of $n(t)$ in a short period of time, followed by an exponential decrease of $n(t)$. This situation may simulate an accident where radionuclides (many of which short-lived) were emitted into the atmosphere over a short time and their presence in air is afterwards reduced 
primarily by radioactive decay. Other similar applications of the formalism are also discussed.

The same approach can be used for other airborne substances decomposable under certain conditions - such as pesticides (3) or nitrogen oxides (4) - or in cases where strong variations in $n(t)$ are suspected, for other reasons, even if a studied substance does not decay. While the inputs to the model depend on a particular situation, the calculation method is the same as in the examples we discuss.

\section{Derivation of the model}

\section{Setting up the model}

In numerous cases, reduction of the number $N$ of given particles (e.g., unstable atoms or molecules) from the initial number $N_{0}=N(t=0)$ follows the rate equation

$$
\frac{d N}{d t}=-\lambda N^{\mu}
$$

where $\lambda>0$ is a constant and $\mu \geq 1$ is an integer. The solution of Eq. [1] is given by $N(t)=N_{0} Y(t)$, where

$$
Y(t)=e^{-\lambda t}, \mu=1,
$$

or

$$
Y(t)=\left[1+(\mu-1) N_{0}^{\mu-1} t\right] \frac{1}{1-\mu}, \quad \mu>1
$$

If air containing particles of a concentration $n$ is pumped through a filter at a rate $\varphi$, the number $N_{\mathrm{F}}$ of the particles adsorbed on the filter obeys

$$
\frac{d N_{\mathrm{F}}}{d t}=-\lambda N_{\mathrm{F}}^{\mu}+n \phi
$$

While the term $-\lambda N_{\mathrm{F}}^{\mu}$ describes the decrease of $N_{\mathrm{F}}$ due to the decay given by Eq. [1], the term $n \varphi$ accounts for the increase of $N_{\mathrm{F}}$ due to new particles being adsorbed on the filter by the pumping. We assume that the sampling commences at $t=0$ and ends at $t=T_{\mathrm{S}}$ when the number of particles on the filter equals $N_{\mathrm{F}}\left(T_{\mathrm{S}}\right)$. In order to determine this number, the filter is processed further by applying appropriate analytical methods, and our goal is to find an expression that relates $N_{\mathrm{F}}\left(T_{\mathrm{S}}\right), n(t)$, and $\varphi(t)$ in general terms.

\section{Derivation of the expression for $N_{F}\left(T_{S}\right.$}

A sketch of a $\varphi\left(0 \leq t \leq T_{\mathrm{S}}\right)$ is given in Fig. 1, the total area under the curve being

$$
V=\int_{0}^{T_{\mathrm{S}}} \phi(t) d t
$$

We subdivide the sampling time using equidistant points $t_{0}=0, t_{1}, \ldots, t_{\mathrm{k}}, \ldots, t_{\mathrm{n}}, T_{\mathrm{s}}$. This fragmentises $V$ into volumes $V_{0}, V_{1}, \ldots, V_{\mathrm{k}}, \ldots, V_{\mathrm{n}}$ such that $V_{\vec{k}} \approx \varphi\left(t_{k}\right) \Delta t$ is pumped during the time interval $\Delta t=t_{k+1}-t_{k}$. The adsorbed number of particles corresponding to this interval is $N_{\mathrm{FF} k}\left(t_{k}\right) \approx n\left(t_{k}\right) V_{k}$. As outlined

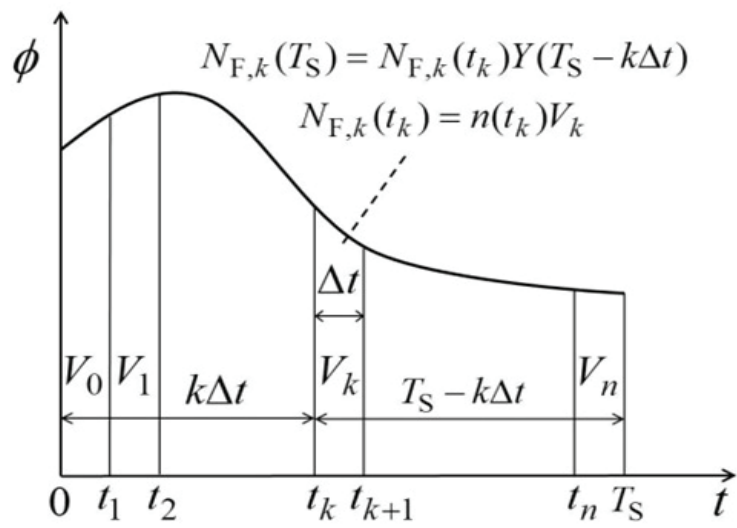

Figure 1 Sketch of a time-dependent $\varphi$, where the elements required for understanding our derivation of $\mathrm{N}_{F}\left(\mathrm{~T}_{S}\right)$ are shown

in Fig. 1, because the time difference between $T_{\mathrm{s}}$ and $t_{k}$ equals $T_{\mathrm{s}}-k \Delta t$, and since $N(t)=N_{0} Y(t)$ applies, the approximate contribution $N_{\mathrm{F}, k}\left(T_{\mathrm{S}}\right)$ of the volume $V_{\mathrm{k}}$ to final $N_{\mathrm{F}}\left(T_{\mathrm{S}}\right)$ is

$N_{\mathrm{F}, k}\left(T_{\mathrm{S}}\right) \approx N_{\mathrm{F}, k}\left(t_{k}\right) Y\left(T_{\mathrm{S}}-k \Delta t\right)=n\left(t_{k}\right) \phi\left(t_{k}\right) Y\left(T_{\mathrm{S}}-k \Delta t\right) \Delta t . \quad[6]$

By summing up all $N_{\mathrm{F}, k}\left(T_{\mathrm{S}}\right)$, we obtain

$N_{\mathrm{F}}\left(T_{\mathrm{S}}\right) \approx \sum_{k=0}^{n} N_{\mathrm{F}, k}\left(T_{\mathrm{S}}\right) \approx \sum_{k=0}^{n} n\left(t_{k}\right) \phi\left(t_{k}\right) Y\left(T_{\mathrm{S}}-k \Delta t\right) \Delta t$

The exact solution is obtained in the continuum limit $(n->\infty, \Delta t->d t, k \Delta t->t)$ where the sum becomes

$$
N_{\mathrm{F}}\left(T_{\mathrm{S}}\right)=\int_{0}^{T_{\mathrm{S}}} n(t) \phi(t) Y\left(T_{\mathrm{S}}-t\right) d t
$$

In Eq. [8], $N_{\mathrm{F}}\left(T_{\mathrm{S}}\right)$ and $\varphi(t)$ can be found experimentally, $Y(t)$ can be inferred by knowing the properties of a substance studied, and $n(t)$ has to be modelled with regard to other available information. Hence, one assesses $n(t)-$ which is central in environmental studies - by comparing experimental indicators and chosen models. If both $Y(t)$ and $n(t)$ are constant, Eq. [8] gives $N_{\mathrm{F}}\left(T_{\mathrm{S}}\right)=n V$, which also holds for Eq. [4].

\section{Investigations of airborne radioactive matter: selected examples}

Radioactive decay follows a first-order $(\mu=1)$ rate equation the solution of which is given by Eq. [2], the halflife being related to $\lambda$ by $T_{1 / 2}=\ln 2 / \lambda$. Once a sampling of air, outlined above, has been completed, one determines the activity $A_{\mathrm{F}}\left(T_{\mathrm{S}}\right)=\lambda N_{\mathrm{F}}\left(T_{\mathrm{S}}\right)$ of the filter. Since the activity concentration in air is yielded by $a(t)=\lambda n(t)$, we use this and Ea. $\lceil 2\rceil$ to write Ea. $\lceil 81$ as

$A_{\mathrm{F}}\left(T_{\mathrm{S}}\right)=e^{-\lambda T_{\mathrm{S}}} \int_{\alpha}^{\beta} a(t) \phi(t) e^{\lambda t} d t$

The integration limits $\alpha$ and $\beta$ may differ from 0 and $T_{\mathrm{S}}$ if $a(t)$ is not non-zero during the entire sampling period. We emphasise that Eq. [9] includes a time-dependent $a(t)$, which, to our knowledge, has not been considered in similar 
approaches. So far, only a constant activity concentration has been assumed, together with either a constant (1) or exponentially decreasing (2) $\varphi(t)$. Below, we exemplify the use of Eq. [9] via six selected combinations of $\varphi(t)$ and $a(t)$.

\section{Example 1: both $\mathrm{a}(\mathrm{t})$ and $\varphi(\mathrm{t})$ are constant}

For constant $\varphi(t)=\varphi(t=0)=\varphi_{0}$ and $a(t)=a_{0}$, we set $\alpha=0$ and $\beta=T_{\mathrm{S}}$ in Eq. [9] to obtain

$$
A_{\mathrm{F}}\left(T_{\mathrm{S}}\right)=a_{0} \phi_{0} \frac{1-e^{-\lambda T_{\mathrm{S}}}}{\lambda} \text {, }
$$

which is the same result as in (1) and it is used to find $a_{0}$ when $T_{1 / 2}$ is smaller than or comparable to $T_{\mathrm{s}}$. A good example of an application of Eq. [10] is the routine monitoring of ${ }^{7} \mathrm{Be}\left(T_{1 / 2}=53.4\right.$ days $)$ when $T_{\mathrm{S}}$ is about a few weeks (5-7). If $T_{1 / 2}>>T_{\mathrm{s}}$, Eq. [10] is reduced to $A_{\mathrm{F}}\left(T_{\mathrm{S}}\right)=a_{0} \varphi_{0} T_{\mathrm{S}}=a_{0} V$, which is used in the monitoring of common long-lived radionuclides in air; e.g., ${ }^{210} \mathrm{~Pb}$ with $T_{1 / 2}=20.4$ years (8), and in other experimental realisations where the above inequality is satisfied (9-13).

\section{Example 2: $\mathrm{a}(\mathrm{t})$ is constant and $\varphi(\mathrm{t})$ decreases exponentially}

It may occur that $\varphi(t)$ changes over time, especially if a large amount of air is sampled (causing the reduction of filter porosity) or there are variations in the performance of a sampler due to either extrinsic or intrinsic causes. One possible form of $\varphi(t)$ is

$\varphi(t)=\varphi_{0} e^{-\gamma t}$

(where $\gamma>0$ ), which was observed (2) for samplings over one week, with $\varphi_{0} \approx 750 \mathrm{~m}^{3} \mathrm{~h}^{-1}$ and $\gamma \approx 0.01 \mathrm{~s}^{-1}$. If we take $a(t)=\mathrm{a}_{0}, \alpha=0, \beta=T_{S}$, and use (11) for $\varphi(t)$, Eq. [9] yields

$A_{\mathrm{F}}\left(T_{\mathrm{S}}\right)=\frac{a_{0}}{\lambda}\left[\left(\phi_{0}+\frac{\phi_{1}}{\lambda}\right)\left(1-e^{-\lambda T_{\mathrm{S}}}\right)-\phi_{1} T_{\mathrm{S}}\right]$,

This is the same result as that obtained in (7), where only this particular situation for $a(t)$ and $\varphi(t)$ was considered. Furthermore, they used an alternative calculation method, i.e., they solved Eq. [4].

\section{Example 3: $\mathrm{a}(\mathrm{t})$ is constant while $\varphi(\mathrm{t})$ decreases linearly}

An exponential drop is not the only experimentally observed decrease of $\varphi(t)$. For our sampling system (a highvolume sampler operating with chlorinated polyvinylchloride filters), we mainly observed

$$
\varphi(t)=\varphi_{0}-\varphi_{1} t
$$

(where $\varphi_{0}, \varphi_{1}>0$ ), with typically $\varphi_{0} \approx 750 \mathrm{~m}^{3} \mathrm{~h}^{-1}$, $\varphi_{1} \approx 2 \mathrm{~m}^{3} \mathrm{~h}^{-2}$, and $T_{\mathrm{s}} \approx 150-350 \mathrm{~h}$. By again assuming that $a(t)=\mathrm{a}_{0}, \alpha=0, \beta=T_{S}$ in Eq. [9], and using (13) for $\varphi(t)$, we obtain
$A_{\mathrm{F}}\left(T_{\mathrm{S}}\right)=\frac{a_{0}}{\lambda}\left[\left(\phi_{0}+\frac{\phi_{1}}{\lambda}\right)\left(1-e^{-\lambda T_{\mathrm{S}}}\right)-\phi_{1} T_{\mathrm{S}}\right],[14]$

which is a result that has not been derived by other authors. Together with previously known results from (10) and (12), the above expression completes the formulae that relate $A_{\mathrm{F}}\left(T_{\mathrm{S}}\right)$ and $a(t)=a_{0}$ for the profiles of $\varphi(t)$ that have, to our knowledge, been reported so far for the sampling of air in radioactivity studies.

\section{Example 4: $\varphi(\mathrm{t})$ is constant and $\mathrm{a}(\mathrm{t})$ decreases exponentially}

The approximation of a constant $a(t)$ is obviously not always applicable. Among numerous possible forms of inconstant $a(t)$, we address one that may simulate an accident in which one or more radionuclides (each with its own $\lambda$ ) were released into the atmosphere during a short time interval around some $t=T_{0}$, which has been followed by an exponential decrease of the corresponding activity concentration in air because of the decay of the emitted radionuclides. An appropriate expression for describing this scenario is

$$
a(t)=a_{\mathrm{m}} e^{-\lambda(t(t)}, t>T_{0}
$$

accounting for a decrease of $a(t)$ from the maximum value $a_{\mathrm{m}}=a\left(T_{0}\right)$. Note that the decay in the air [reflecting the decrease of $n(t)]$ is treated separately from the decay on the filter, the latter being accounted for in Eqs. [8] and [9] via the function $Y(t)=\exp (-\lambda t)$. Since $T_{0}$ is known, as well as $\lambda$ of a given radionuclide, in order to reconstruct $a(t)$, one should find a relation between $A_{\mathrm{F}}\left(T_{\mathrm{S}}\right)$ and $a_{\mathrm{m}}$.

There are two possible situations with regard to the sampling period $\left(0 \leq t \leq T_{\mathrm{S}}\right)$ and $T_{0}$, which is depicted in Fig. 2 . The first possibility is described by the curve labelled 1 (where $T_{0}=T_{0,1} \geq 0$ ), for which the emission occurs during the sampling. In the second case (the curve labelled 2, with $T_{0}=T_{0,2}<0$ ), sampling starts after emission has occurred.

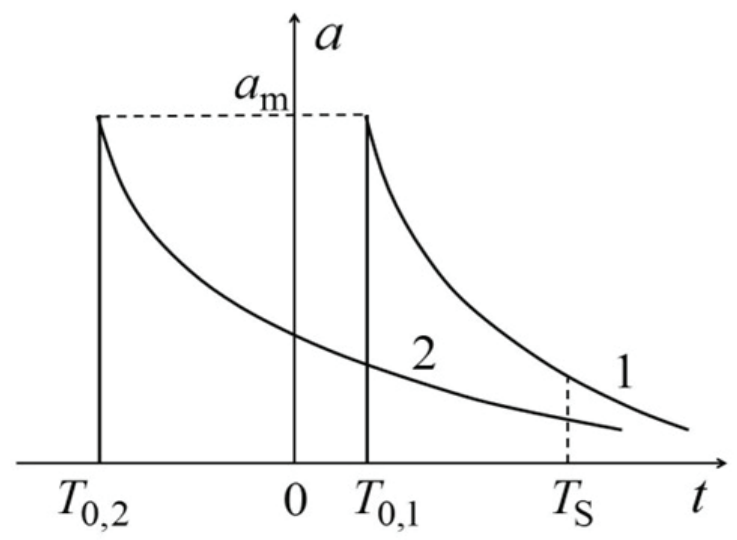

Figure 2 Sudden increase of $\mathrm{a}(\mathrm{t})$, followed by a decrease due to the decay of the emitted radionuclide. Two curves labelled 1 and 2 depict two possible situations with regard to the emission time and sampling period, see the text for details 
We first consider the case of $\varphi(t)=\varphi(t=0)=\varphi_{0}$. For $T_{0} \geq 0$ (curve 1 in Fig. 2), we combine Eqs. [9] and [15] by setting $\alpha=T_{0}$ and $\beta=T_{\mathrm{S}}$, which results in

$$
A_{\mathrm{F}}\left(T_{\mathrm{S}}\right)=a_{\mathrm{m}} \phi_{0} e^{-\lambda\left(T_{\mathrm{S}}-T_{0}\right)}\left(T_{\mathrm{S}}-T_{0}\right) .
$$

When $T_{0}<0$ (curve 2 in Fig. 2), we set $\alpha=0$ and $\beta=T_{\mathrm{S}}$ to obtain

$$
A_{\mathrm{F}}\left(T_{\mathrm{S}}\right)=a_{\mathrm{m}} \phi_{0} e^{-\lambda\left(T_{\mathrm{S}}+\left|T_{0}\right|\right)} T_{\mathrm{S}} .
$$

\section{Example 5: both $\mathrm{a}(\mathrm{t})$ and $\varphi(\mathrm{t})$ decrease exponentially}

As before, we extend the calculation of $A_{\mathrm{F}}\left(T_{\mathrm{S}}\right)$ for $a(t)$ given by Eq. [15] to the experimentally observed inconstant forms of $\varphi(t)$. We first consider an exponentially decreasing $\varphi(t)$ given by Eq. [11]. Using the same procedure as above, we obtain

$$
A_{\mathrm{F}}\left(T_{\mathrm{S}}\right)=a_{\mathrm{m}} \phi_{0} e^{-\lambda\left(T_{\mathrm{S}}-T_{0}\right)} \frac{e^{-\gamma T_{0}}-e^{-\gamma T_{\mathrm{S}}}}{\gamma}
$$

for $T_{0} \geq 0$, and

$$
A_{\mathrm{F}}\left(T_{\mathrm{S}}\right)=a_{\mathrm{m}} \phi_{0} e^{-\lambda\left(T_{\mathrm{S}}+T_{0} \mid\right)} \frac{1-e^{-\gamma T_{\mathrm{S}}}}{\gamma}
$$

for $T_{0}<0$.

\section{Example 6: $\mathrm{a}(\mathrm{t})$ decreases exponentially and $\varphi(\mathrm{t})$} decreases linearly

We conclude the examples of applications of the presented formalism by turning to the combination of linear $\varphi(t)=\varphi_{0}-\varphi_{1} t$ and $a(t)$ given by Eq. [15]. By the same method as in the above two examples, we find

$$
A_{\mathrm{F}}\left(T_{\mathrm{S}}\right)=a_{\mathrm{m}} e^{-\lambda\left(T_{\mathrm{S}}-T_{0}\right)}\left[\phi_{0}\left(T_{\mathrm{S}}-T_{0}\right)-\frac{\phi_{1}}{2}\left(T_{S}^{2}-T_{0}^{2}\right)\right]
$$

for $T_{0} \geq 0$, and

$$
A_{\mathrm{F}}\left(T_{\mathrm{S}}\right)=a_{\mathrm{m}} e^{-\lambda\left(T_{\mathrm{S}}+T_{0}\right)}\left[\phi_{0} T_{\mathrm{S}}-\frac{\phi_{1}}{2} T_{\mathrm{S}}^{2}\right]
$$

for $T_{0}<0$.

\section{An example of the experimental use of the model}

We complete this paper by addressing the practical use of the presented approach. Since there has been no recent accidental situation that would lead to a modelling similar to that in Examples 4, 5, and 6, we turn to data available from routine monitoring of common radionuclides in air. In Fig. 3, we first demonstrate typical $\varphi(t)$ data for our high-volume sampler, where it is rather clear that the $\varphi(t)$ in our case decreases linearly.

One of the main sources of radioactivity in air is ${ }^{7} \mathrm{Be}$ with $T_{1 / 2}=53.4$, which is a naturally occurring radionuclide with a constant presence due to its cosmogenic origin. The sampling under consideration was carried out for $T_{\mathrm{s}}=223.23$ $\mathrm{h}$, and $\varphi(t)$ was decreasing linearly with $\varphi_{0}=762 \pm 18 \mathrm{~m}^{3} \mathrm{~h}^{-1}$

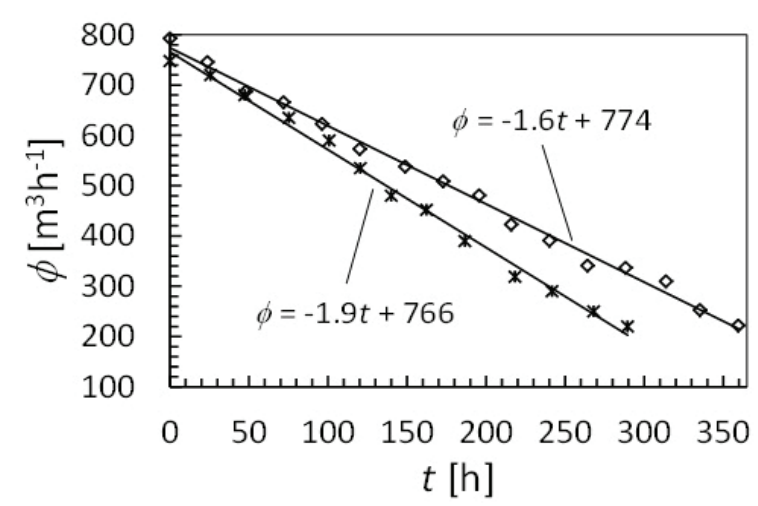

Figure 3 Two typical experimental $\varphi(\mathrm{t})$ for our sampling system, obviously exhibiting a linear dependence

and $\varphi_{1}=2.24 \pm 012 \mathrm{~m}^{3} \mathrm{~h}^{-2}$; hence, the pumped air volume was $V=\varphi_{0} T_{\mathrm{S}}=\varphi_{1} T_{\mathrm{S}}^{2}=58478.4 \mathrm{~m}^{3}$. Because of a relatively short $T_{\mathrm{S}}$ and the absence of any unusual conditions during the sampling, it is reasonable to assume that the concentration of ${ }^{7} \mathrm{Be}$ in air was fairly constant and that $a(t)=a_{0}$ and Eq. [14] apply.

By means of gamma-ray spectrometry, we measured $a_{\mathrm{F}}\left(T_{\mathrm{S}}\right)=A_{\mathrm{F}}\left(T_{\mathrm{S}}\right) / V=3.713 \pm 0.010 \mathrm{~m} \mathrm{~Bq} \mathrm{~m}^{-3}$, whereas Eq. [14] yields $a_{0}=3.750 \pm 0.011 \mathrm{~m} \mathrm{~Bq} \mathrm{~m}^{-3}$ (in $a_{\mathrm{F}}\left(T_{\mathrm{S}}\right)$ and $a_{0}$, the uncertainties of $\varphi_{0}, \varphi_{1}$, as well as those arising from gammaray spectrometry, are taken into account). Their relative difference $\left[a_{0}-a_{\mathrm{F}}\left(T_{\mathrm{S}}\right)\right] / a_{\mathrm{F}}\left(T_{\mathrm{S}}=0.01\right)$ is rather small but is nevertheless statistically significant. The reason is that the uncertainties $\delta_{\mathrm{F}}$ and $\delta_{0}$ and of $a_{\mathrm{F}}\left(T_{\mathrm{S}}\right)$ and $a_{0}$, respectively, are small enough that the two results do not overlap. Namely, $\left[a_{0}-a_{\mathrm{F}}\left(T_{\mathrm{S}}\right)\right] /\left[\delta_{0}+\delta_{\mathrm{F}}\right]=1.79$ is larger than unity and the two results are consequently distinguishable. This should not be disregarded if analytical accuracy is pursued in the spirit of quality assurance procedures (14).

\section{Outlook}

The above six examples of the use of Eq. [9] cover the combinations of three experimentally observed $\varphi(t)$ dependences and two profiles of $a(t)$ that can be linked to certain situations of practical relevance. Owing to the generality of Eq. [9] and, implicitly, of Eq. [8], these calculations can be extended further using either analytical or numerical integration.

An interesting phenomenon to mention is the gradual increase of $n(t)$ until it reaches a maximum and then continues to decrease gradually, which is also a viable scenario in environmental studies. Mathematically, one could in this case model $n(t)$ by a number of peaked functions such as symmetric Gaussian, Lorentzian, or parabolic functions, various similar non-symmetric functions, etc., each containing two or more parameters that define their shapes. Since the success of the presented formalism depends on reducing the number of adjustable parameters, it is desirable to put some effort in fixing as many parameters as possible. For instance, in our examples 
3-6, the fixed parameter is $T_{0}$ which is assumed to be known a priori, and the full profile of $a(t)$ is then obtained by finding only one unknown parameter, that is, $a_{m}$. Hence, our formalism provides a versatile and robust tool but it requires careful approach in every particular situation.

Developing these calculations, i.e. implementing formulas such as the ones observed by this paper into, for instance, a comprehensive urban air monitoring network, would constitute the next logical step, as other authors have proposed (15).

\section{CONCLUSIONS}

Generally, interpreting the number $N_{\mathrm{F}}$ of particles adsorbed on a filter through which a certain volume $V$ of air was pumped is no easy task. This complexity stems from possible time $(t)$ dependences of the quantities that contribute to $N_{\mathrm{F}}$, these being the concentration $n$ of an airborne substance of interest, the flow rate $\varphi$ through the sampling filter, and the decay law $Y(t)$ if the substance is decomposable. In numerous cases, the expression $N_{\mathrm{F}}=n V$, where $n$ is assumed to be constant, oversimplifies the actual situation. We have developed a formalism that links $N_{\mathrm{F}}$ to a time dependent $n(t), \varphi(t)$, and $Y(t)$, which results in a compact single expression of general applicability. Applications of the expression were exemplified by addressing airborne radioactive matter, for which $Y(t)$ is well known. Three experimentally reported profiles of $\varphi(t)$ were combined with two modelled $n(t)$ dependences and these examples both demonstrate the validity of the expression, possibly offering solutions for certain other, potentially important problems.

\section{REFERENCES}

1. International Electrotechnical Commission (IEC). IEC 61452:1995. Nuclear instrumentation - Measurement of gamma-ray emission rates of radionuclides - Calibration and use of germanium spectrometers.

2. Jiménez-Ramos MC, Manjón G, Abril JM. Influence of sampling air flow rate in the decay correction applied to the determination of ${ }^{7} \mathrm{Be}$ and short-lived radionuclides in aerosol samples. Atm Environ 2006;40:7215-21. doi: 10.1016/j. atmosenv.2006.06.019

3. Burrows HD, Canle LM, Santaballa JA, Steenken S. Reaction pathways and mechanisms of photodegradation of pesticides. J Photochem Photobiol B 2002;67:71-108. doi: 10.1016/ S1011-1344(02)00277-4
4. Preston KF, Cvetanović RJ. The decomposition of inorganic oxides and sulphides, in Decomposition of inorganic and organometallic compounds. In: Bamford $\mathrm{CH}$, Compton RG, Tipper CFH, editors: Decomposition of inorganic and organometallic compounds. Chapeter 2. Amsterdam: Elsevier; 1972. p. 47-141.

5. Baeza A, Rio LM, del Jiménez A, Miró C, Paniagua JM, Rufo M. Analysis of the temporal evolution of atmospheric ${ }^{7} \mathrm{Be}$ as a vector of the behaviour of other radionuclides in the atmosphere. J Radioanal Nuclear Chem 1996;207:331-4. doi: 10.1007/BF02071239

6. Dueñas C, Fernández MC, Liger E, Carretero J. Gross alpha, gross beta and ${ }^{7} \mathrm{Be}$ concentrations in surface air: analysis of their variations and prediction model. Atm Environ 1999;33:3705-15. doi: 10.1016/S1352-2310(99)00172-7

7. Ródenas C, Gómez J, Quindós LS, Fernández PL, Soto J. ${ }^{7} \mathrm{Be}$ concentrations in air, rainwater and soil in Cantabria (Spain). Appl Radiat Isot 1997;48:545-8. doi: 10.1016/ S0969-8043(96)00295-3

8. Vecchi R, Marcazzan G, Valli G. Seasonal variation of ${ }^{210} \mathrm{~Pb}$ activity concentration in outdoor air of Milan (Italy). J Environ Radioact 2005;82:251-66. doi: 10.1016/j. jenvrad.2004.12.008

9. Franić Z, Šega K, Petrinec B, Marović G. Long-term investigations of post-Chernobyl radiocaesium in fallout and air in North Croatia. Environ Monit Assess 2009;148:315-23. doi: 10.1007/s10661-008-0162-4

10. Gerasopoulos E, Zerefos CS, Papastefanou C, Zanis P, O'Brien K. Low-frequency variability of Beryllium-7 surface concentrations over the Eastern Mediterranean. Atm Environ 2003;37:1745-56. doi: 10.1016/S1352-2310(03)00068-2

11. Todorović D, Popović D, Djurić G. Concentration measurements of ${ }^{7} \mathrm{Be}$ and $137 \mathrm{Cs}$ in ground-level air in the Belgrade City area. Environ Int 1999;25:59-66. doi: 10.1016/ S0160-4120(98)00099-3

12. Vecchi R, Valli G. ${ }^{7} \mathrm{Be}$ in surface air: a natural atmospheric tracer. J Aerosol Sci 1997;28:895-900. doi: 10.1016/S00218502(97)88763-0

13. Yu KN, Lee LYL. Measurement of atmospheric ${ }^{7} \mathrm{Be}$ properties using high-efficiency gamma spectroscopy. Appl Radiat Isot 2002;57:941-6. doi: 10.1016/S09698043(02)00229-4

14. Petrinec B, Franić Z, Bituh T, Babić D. Quality assurance in gamma-ray spectrometry of seabed sediments. Arh Hig Rada Toksikol 2011;62:17-23. doi: 10.2478/10004-1254-62-20112078

15. Davila S, Pečar Ilić J, Bešlić I. Real-time dissemination of air quality information using data streams and Web technologies: linking air quality to health risks in urban areas. Arh Hig Rada Toksikol 2015;66:171-80. doi: 10.1515/aiht2015-66-2633 


\section{Uzorkovanje zraka pumpanjem kroz filtar: učinci brzine strujanja i koncentracije zraka i raspadanja spojeva}

Tema je ovoga rada problem s brojem lebdećih čestica apsorbiranih na filtar kroz koji je pumpan i time uzorkovan određeni volumen zraka. Taj broj jednak je umnošku uzorkovanog volumena i koncentracije čestica samo ako je protok stalan u vremenu i nema raspada tvari na filtru tijekom uzorkovanja. U protivnom se mora uzeti u obzir zakon raspada za određenu tvar, što se još više komplicira ako protok kroz filtar nije konstantan. Razvili smo formalizam koji uključuje sve ove čimbenike, što je rezultiralo jednim kompaktnim izrazom opće primjenjivosti. Uporaba ovoga izraza demonstrirana je na slučaju uzorkovanja radioaktivnih tvari u zraku, za koje je zakon radioaktivnoga raspada dobro poznat. Taj je zakon kombiniran s trima eksperimentalno opaženim vremenskim ovisnostima protoka i dvama modelima za vremensku ovisnost koncentracije čestica. Također je diskutirana primjena tih izračuna u nekim drugim interesnim situacijama u istraživanjima okoliša.

KLJUČNE RIJEČI: uzorkovanje zraka; koncentracija čestica; protok; radioaktivnost; raspad tvari 